Published in final edited form as:

Genes Brain Behav. 2018 July ; 17(6): e12461. doi:10.1111/gbb.12461.

\title{
Cognitive deficits and increases in creatine precursors in a brain-specific knockout of the creatine transporter gene SIc6a8
}

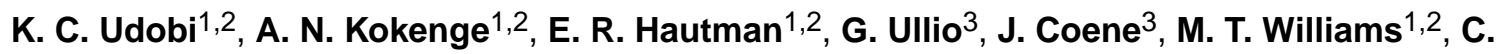 \\ V. Vorhees ${ }^{1,2}$, A. Mabondzo ${ }^{3}$, M. R. Skelton ${ }^{1,2}$ \\ ${ }^{1}$ Department of Pediatrics, University of Cincinnati College of Medicine, Cincinnati, Ohio \\ 2Division of Neurology, Cincinnati Children's Research Foundation, Cincinnati, Ohio \\ ${ }^{3}$ Service de Pharmacologie et Immunoanalyse (SPI), CEA, Université Paris Saclay, Gif-sur-Yvette \\ Cedex, France
}

\section{Abstract}

Creatine transporter (CrT; SLC6A8) deficiency (CTD) is an X-linked disorder characterized by severe cognitive deficits, impairments in language and an absence of brain creatine $(\mathrm{Cr})$. In a previous study, we generated floxed Slc6a8 (Slc6a8 ${ }^{\text {flox }}$ ) mice to create ubiquitous Slc6a8 knock

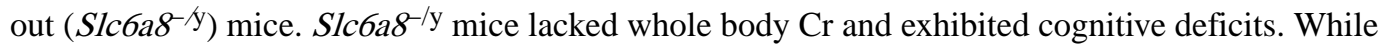
SIc6a $8^{-/ y}$ mice have a similar biochemical phenotype to CTD patients, they also showed a reduction in size and reductions in swim speed that may have contributed to the observed deficits. To address this, we created brain-specific Slc6a8 knockout (bKO) mice by crossing Slc6a $8^{\text {flox }}$ mice with Nestin-cre mice. bKO mice had reduced cerebral $\mathrm{Cr}$ levels while maintaining normal $\mathrm{Cr}$ levels in peripheral tissue. Interestingly, brain concentrations of the $\mathrm{Cr}$ synthesis precursor guanidinoacetic acid were increased in bKO mice. bKO mice had longer latencies and path lengths in the Morris water maze, without reductions in swim speed. In accordance with data from Slc6a $8^{-/ y}$ mice, bKO mice showed deficits in novel object recognition as well as contextual and cued fear conditioning. bKO mice were also hyperactive, in contrast with data from the Slc6a8-1y mice. The results show that the loss of cerebral $\mathrm{Cr}$ is responsible for the learning and memory deficits seen in ubiquitous $S / c 6 a 8^{-1 /}$ mice.

\section{Keywords}

conditioned fear; creatine; creatine transporter; guanidinoacetic acid; hyperactivity; learning and memory; Morris water maze; Nestin-Cre; object recognition memory

\section{1| INTRODUCTION}

The absence of the high-energy phosphate buffer creatine $(\mathrm{Cr})$ in the brain leads to intellectual disability (ID), language impairment and epilepsy. ${ }^{1}$ There are currently 3 known

Correspondence: M. R. Skelton, PhD, Division of Neurology, Cincinnati Children's Research Foundation, 3333 Burnet Avenue, MLC 7044, Cincinnati, OH 45229-3039., matthew.skelton@ cchmc.org.

Conflict of interest

The authors declare no competing interests. 
causes of cerebral $\mathrm{Cr}$ deficiency, of which $\mathrm{Cr}$ transporter (CrT; SLC6A8) deficiency (CTD) is the most prevalent. CTD has been estimated to be one of the leading causes of X-linked ID (XLID) in males ${ }^{2-4}$; however, little is known about the mechanisms underlying the cognitive deficits. To better understand the underlying patholophysiology of CTD, we generated mice with exons 2 to 4 of the murine Slc6a8 gene flanked with LoxP sites $\left(\right.$ Slc6a $\left.{ }^{f l o x}\right)$. The primary goal in developing this model is to produce a high-fidelity model of CTD that recapitulates as much of the phenotype of human CTD patients as possible. In our first study, ubiquitous Slc6a8 knockout $\left(S / c 6 a 8^{-/ y}\right)$ mice were derived from Slc6a $8^{\text {flox }}$ mice. ${ }^{5}$ Consistent with human CTD, the $S / c 6 a 8^{-/ y}$ mice show an absence of brain $\mathrm{Cr}$ and cognitive deficits. Slc6a ${ }^{-/ y}$ mice also had reduced body mass and a near absence of $\mathrm{Cr}$ in most tissues, including the muscle. ${ }^{5}$ The reduction of muscle $\mathrm{Cr}$ in $S 1 c 6 a 8^{-1 y}$ mice may be inconsistent with the limited data from human CTD showing normal muscle $\mathrm{Cr}$ levels. ${ }^{6,7}$ Further, the reduced size and loss of muscle $\mathrm{Cr}$ could influence the behavioral deficits observed in the $S l c 6 a 8^{-1 y}$ mice, because many of these tasks require physical movement. For example, $S I c 6 a 8^{-/ y}$ mice swam slower than $S l c 6 a 8^{+/ y}$ mice in the Morris water maze (MWM), which may have affected navigating to the hidden platform. ${ }^{5}$ This confound could reduce the translational value of this animal. By creating SIc6asflox mice, we are able to assess potential confounds using tissue-specific expression of Cre-recombinase.

Using the floxed $\operatorname{Slc6a8}\left(\right.$ Slc6a $^{\text {flox/y }}$; FLOX) mouse line from Skelton et al's ${ }^{5}$ study, Kurosawa et $\mathrm{al}^{8}$ created a partial Slc6a 8 brain knockout mouse using a Camk2a-cre expressing mouse. The Camk2a-cre mouse expresses Cre recombinase in excitatory neurons in the forebrain. ${ }^{9}$ Similar to the Slc6a8 ${ }^{-/ y}$ mice, the Slc6a $8^{\text {flox/- }}$ Camk2a mice showed spatial learning and novel object deficits. ${ }^{8}$ Interestingly, the spatial learning deficits were observed only when the last 3 days of testing were analyzed separately; in comparison $S 1 c 6 a 8^{-/ y}$ mice showed a robust deficit throughout testing. This would suggest that there could be some motor contribution to the deficit seen in $S 1 c 6 a \delta^{-/ y}$ mice; however, the selection of the Camk2a mouse is somewhat problematic. This is due to Camk2a-cre expression being limited to excitatory neurons in the forebrain; allowing for the possibility that some $\mathrm{Cr}$ mediated function was spared. The Nestin promoter drives Cre-recombinase expression in neuronal precursor cells, creating a more complete brain-specific knockout. ${ }^{10}$ The differences in these Cre-expressing mice are highlighted by a recent study that showed that the offspring from floxed $C c 2 d l a$ mice crossed to Nestin-cre mice died at birth while the offspring from floxed mice crossed with Camk2a-cre mice were viable. ${ }^{11}$ The use of "Nestin-cre mice" allows for a more complete understanding of the contributions of brain $\mathrm{Cr}$ to behavioral performance.

Recently, an additional mouse model of CTD has been created by flanking exons 5 to 7 of the Slc6a8 gene with LoxP sites. ${ }^{12}$ Similar to the Slc6a8 $(2-4)^{-/ y}$ mice of Skelton et al, ${ }^{5}$ ubiquitous knockout $\left(\operatorname{Slc6a8}\left(5-7^{-1}\right)\right.$ mice from this line showed reduced body weight and deficits in novel object recognition (NOR) compared with $S / c 6 a 8^{+/ y}$ mice. Similar to the

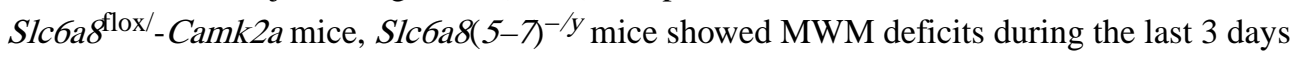
of testing. ${ }^{12}$ In a subsequent study, Slc6a $8(5-7)^{\text {flox/y }}$ mice were crossed to Nestin-cre mice to create brain-specific knockout mice. These mice show deficits in NOR and Y-maze performance. ${ }^{13}$ While this supports the hypothesis that the effects are centrally mediated, the lack of MWM testing in these mice still leaves the possibility that the larger spatial learning 


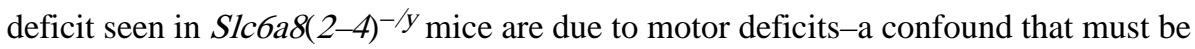
resolved in order to properly model this disorder.

The purpose of this study was to determine if the cognitive deficits seen in the Slc6a $8^{-1 y}$ mice were due to a lack of cerebral Cr by testing brain-specific Slc6a8 knockout (bKO) mice. The behavioral tests used in this study have been shown to be disrupted in Slc6a $8^{-1 y}$ mice ${ }^{5,14}$ and represent 3 distinct types of learning with different neuroanatomical basis. The results of this study show that bKO mice have MWM deficits similar to those seen in the ubiquitous $S 1 c 6 a 8^{-/ y}$ mice without reductions in swim speed. In addition, reductions in NOR and conditioned fear memory were observed in bKO mice. This would suggest that the deficits observed in the $S / c 6 a 8^{-/ y}$ mice are central cognitive impairments, analogous to those seen in CTD patients.

\section{2 | METHODS}

\subsection{Generation of bKO mice}

The bKO mice were generated and maintained on a C57BL/6J background in a pathogenfree facility in microisolators. Female $S / c 6 a 8^{\text {flox/+ }}$ mice, generated and genotyped as described, ${ }^{5}$ were mated to mice expressing Cre recombinase driven by the Nestin promoter (B6.Cg-Tg (Nes-cre) $^{1 \mathrm{Kln} / \mathrm{J}}$; Jackson laboratory, Bar Harbor, Maine) to create the mice used

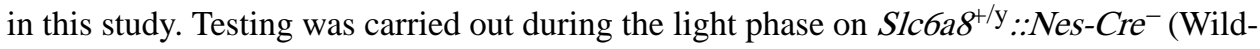
type; WT), bKO, Slc6a ${ }^{+/ y}:: N e s-C r e^{+}$(Nestin) and FLOX mice. Female mice were not used as heterozygous female $S / c 6 a 8^{+/}$mice did not show reduced size or swim speed deficits. ${ }^{14}$ No more than one mouse per genotype was taken from a litter. All procedures on mice were performed at the CCRF vivarium which is fully accredited by the Association for Assessment and Accreditation of Laboratory Animal Care International and protocols were approved by the Institutional Animal Care and Use Committee. Mice were housed on a 14:10 light:dark cycle with the room temperature maintained at $19^{\circ} \mathrm{C} \pm 1{ }^{\circ} \mathrm{C}$. Food and filtered, sterilized water were available ad libitum. All institutional and national guidelines for the care and use of laboratory animals were followed.

\section{2 | Behavioral testing}

Adult (between 60 and 90 days old) male mice of each genotype ( $n=14 \mathrm{WT} ; 15 \mathrm{bKO} ; 23$ FLOX; 12 Nestin) were used. Mice were weighed on the first day of testing. Testing occurred in the order of presentation with 1 day between new tasks.

\subsection{Locomotor activity}

Spontaneous locomotor activity ${ }^{15}$ was tested in automated activity chambers, photobeam activity system (PAS)-open-field (San Diego Instruments, San Diego, California) for 1 hour. Chambers were $40 \mathrm{~cm}(\mathrm{~W}) \times 40 \mathrm{~cm}(\mathrm{D}) \times 38 \mathrm{~cm}(\mathrm{H})$ with 16 LED-photodetector beams in $\mathrm{X}$ and $\mathrm{Y}$ planes. Photocells were spaced $2.5 \mathrm{~cm}$ apart. Mice were tested for 1 hour. The dependent measure was total number of photobeams interruptions. 


\section{4 | Morris water maze}

The MWM is a test of spatial learning and reference memory ${ }^{16}$; mice were tested as described. ${ }^{5}$ The tank was $122 \mathrm{~cm}$ in diameter, white and filled with room temperature $\left(21^{\circ} \mathrm{C}\right.$ $\pm 1^{\circ} \mathrm{C}$ ) water. Prior tohidden platform testing, visible platform training (cued) was conducted for 6 days. During this phase, a $10 \mathrm{~cm}$ diameter platform with an orange ball mounted above the water on a brass rod was placed in one quadrant. On day 1, mice were given 6 trials with identical start and platform positions as training for the task. Mice were then given 2 trials per day for 5 days with the start and platform positions randomized and curtains closed around the pool to obscure distal cues to assess proximal cue learning.

Hidden platform trials were conducted in 2 phases; each phase consisted of 4 trials per day for 6 days followed by a single probe trial without the platform on day 7. Platform diameters were $10 \mathrm{~cm}$ during acquisition and $7 \mathrm{~cm}$ during reversal (platform located in the opposite quadrant). Reducing the size of the platform between acquisition and reversal increases the difficulty of the task and may be used to uncover spatial deficits. ${ }^{16}$ The trial limit was 90 seconds and the intertrial interval (ITI) was approximately 10 seconds. Mice that failed to find the platform were placed on the platform and given the same 10 seconds ITI. Performance was measured using ANY-maze software (Stoelting Company, Wood Dale, Illinois).

\subsection{Novel object recognition}

NOR is a test of incidental learning and memory. ${ }^{17}$ Mice were tested in the ANY-box apparatus (Stoelting Company). First, mice were habituated to the arena $(40 \times 40 \mathrm{~cm})$ for 2 days $(10 \mathrm{~min} / \mathrm{d})$; next they were then habituated to 2 identical objects $(10 \mathrm{~min} / \mathrm{d})$ for 2 days to reduce neophobia. ${ }^{18}$ On the fifth day, mice were presented with 2 new identical objects until 30 seconds of observation time between objects was accrued. One hour later, memory was tested by presenting the mouse with an identical copy of one of the familiar objects along with a novel object. Time exploring an object was defined as entry into a $2 \mathrm{~cm}$ zone around the object. Performance was measured using ANY-maze software. A subset of animals ( $n=3$ from each group) were randomly selected and hand scored to determine if the software accurately tracked the animals. The software-tracked time was highly correlated ( $r$ $=0.89, P<.001)$ with the hand-scored time, suggesting the software accurately tracks the animals. A discrimination index was calculated: time observing the novel object was subtracted from the time observing the familiar object, divided by total object observation time.

\subsection{Conditioned fear}

Conditioned fear was assessed as described with modification. ${ }^{19}$ On day 1 , mice were placed in a chamber for 10 minutes before exposure to 3 tone-footshock pairings $(82 \mathrm{~dB}, 2 \mathrm{kHz}, 30$ seconds on/off cycle). Each pairing consisted of the 30 seconds tone accompanied during the last second by a scrambled footshock ( $0.3 \mathrm{~mA}$ for 1 second) delivered through the floor. On the second day, mice were returned to the chamber with no tone or shock as a test of contextual fear. On the third day, mice were placed in the chamber with a novel floor. Following 3 minutes of acclimation, the tone was presented for 3 minutes. On days 2 and 3 
freezing behavior was scored. Freezeframe software and Coulbourn test chambers were used (Coulbourn Instruments, Allentown, Pennsylvania). Percent time freezing was analyzed.

\section{7| Cr and guanidinoacetic acid determination}

Following behavioral testing a subset of mice were sacrificed by decapitation. Brains were divided into hemispheres and flash frozen. $\mathrm{Cr}$ and guanidinoacetic acid (GAA) content were assayed in brain, heart and kidney using a Ultra performance liquid chromatography, tandem mass spectrometry (UPLC-MS/MS) method. ${ }^{20}$ First, $20 \mu \mathrm{L}$ from each brain homogenate (diluted 1/10) was spiked with $5 \mu \mathrm{L}$ of internal standard solution (creatine-D3: $0.5 \mu \mathrm{g} / \mathrm{mL}$ ) and $175 \mu \mathrm{L}$ of water were added to reach $200 \mu \mathrm{L}$ final volume. For liquid-liquid extraction, $400 \mu \mathrm{L}$ ethanol and $400 \mu \mathrm{L}$ hexane were added and the mixture was centrifuged at $4^{\circ} \mathrm{C}$ for 15 minutes $(10000 \mathrm{~g})$. Then, the upper phase was discarded and the hexane step was repeated one more time. Finally, the lower phase was transferred into a clean tube and evaporated to dryness under a gentle stream of nitrogen at $40^{\circ} \mathrm{C}$. Then, the samples were added with $200 \mu \mathrm{L}$ of hydrogen chloride-1-butanol ( $₫ 99 \%$ HPLC Sigma-Aldrich, Paris, France) and placed in a Thermomixer at $65^{\circ} \mathrm{C}$ for 15 minutes followed by an evaporation step. The residue was reconstituted with $100 \mu \mathrm{L}$ of water injected into the LC-MS/MS system. The analytical method was performed with a binary pumps LC-30AD (Shimadzu Nexera X2) and compounds (Cr, GAA, creatine-D3) were separated by injecting extracted samples $(10 \mu \mathrm{L})$ on a $\mathrm{C} 18$ symmetry column-Waters $(50 \times 2.1 \mathrm{~mm})$, with a $3.5 \mu \mathrm{m}$ particles size maintained at $30^{\circ} \mathrm{C}$. The mobile phase consisted of phase $\mathrm{A}(0.1 \%$ formic acid in water $)$ and phase B ( $0.1 \%$ formic acid in acetonitrile) on isocratic mode. Each analysis was carried out for 8 minutes and the flow rate of $0.4 \mathrm{~mL} / \mathrm{min}$ was used for the sample analysis.

Detection was performed with a triple quadrupole mass spectrometer TSQ Quantum Ultra (Thermo Scientific, Villebon-sur-Yvette, France) equipped with electrospray ionization source (ESI) in the positive ion mode. The equipment was set up in a multiple reaction monitoring (MRM) mode and the optimized setting parameters were: ion spray voltage 3000 $\mathrm{V}$, source temperature $350^{\circ} \mathrm{C}$, sheath gas pressure 23 , followed transitions for quantification: Cr-derivative: $188.18 \rightarrow 90.20 ; 132.07$ and 146.15 (Collision energy: 20); creatine-D3 derivative: $190.93 \rightarrow 93.21 ; 134.87$ and 149.23 (Collision energy: 20); GAA derivative: $174.09 \rightarrow 72.75 ; 100.75$ and 117.75 (Collision energy: 20). Results were recorded by Xcalibur and TSQ Tune Master (Thermo). The amount of $\mathrm{Cr}$ and GAA were standardized to the amount of protein in each homogenate tissue by the Bradford technique following the manufacturer's instruction (Sigma-Aldrich).

\subsection{Statistics}

Data were analyzed using 1-way analysis of variance (ANOVA) except when there were repeated measurements on the same mouse (interval or day) in which case they were analyzed by repeated-measures ANOVA. Significant effects were analyzed using the method of Benjamini et al. ${ }^{21}$ Data were analyzed using GraphPad Prism (La Jolla, CA). 


\section{3 | RESULTS}

\section{1 | Body weight}

Mice were weighed on the first day of testing. No significant differences were observed in body weight between WT $(26.4 \pm 0.6 \mathrm{~g})$, FLOX $(25.6 \pm 0.6 \mathrm{~g})$, Nestin $(25.3 \pm 1.0 \mathrm{~g})$ and bKO $(25.3 \pm 0.6 \mathrm{~g})$ mice.

\subsection{Cr and GAA levels}

3.2.1 Brain-There were main effects of gene for $\operatorname{Cr}\left(F_{3,13}=39.94, P<.001\right)$ and GAA $\left(F_{3,13}=4.3, P<.05\right)$ levels (Figure 1A,B). Significant reductions in $\mathrm{Cr}$ were observed in bKO mice compared with WT, FLOX and Nestin mice. There was a slight reduction in $\mathrm{Cr}$ levels in Nestin mice compared with WT mice $(P<0.05)$ but not in FLOX mice. No differences were observed between FLOX and WT mice. GAA levels were increased in bKO mice compared with the control groups $(P<.05)$. No differences were observed between control groups for GAA.

3.2.2 Peripheral tissues-There was no effect of gene on Cr or GAA levels in the heart (Figure 1C,D). There was no effect of gene on Cr or GAA levels in the kidney (Figure 1E,F). There was no effect of gene on Cr or GAA levels in the muscle or liver (not shown for clarity).

\subsection{Locomotor activity}

There was a significant main effect of gene $\left(F_{3,54}=21.9 ; P<.001\right.$; Figure 2$)$ for total activity. A gene $\times$ time interaction $\left(F_{33}, 594=2.0, P<.01\right)$ was observed. bKO mice showed increased activity compared with all other groups $(P<.05)$ at all times. FLOX mice showed hyperactivity compared with WT and Nestin mice at 15, 35 and 60 minutes. No differences were observed between WT and Nestin groups.

\subsection{Morris water maze}

On day 1 cued training, there was trend toward a main effect of gene $\left(F_{3,73}=2.6, P<.07\right)$. An increase in latency was seen on days 2 to 6 (main effect of gene: $F_{3,73}=6.03, P<.01$ ). No differences were observed between the control groups.

For hidden platform testing, latency and path length were well correlated $(r=0.832, P<$. 001 ), therefore, path length is presented to remain consistent with our previous studies. During acquisition, bKO mice had an increased path length compared with control groups $\left(F_{3,72}=13.4, P<.001\right.$; all post hoc tests $P<.01$ vs control groups; Figure $\left.3 \mathrm{~A}\right)$. No differences were observed between control groups. There were no significant effects of gene on swim speed. During the acquisition probe trial, bKO mice had a greater average distance from the former platform site compared with the WT mice (main effect of gene: $F_{3,72}=5.0$, $P<.001$; bKO vs WT $P<.05$, Figure 3C). Learning curves for the WT vs bKO mice are shown in Figure 3E.

During reversal, there was a main effect of gene for path length $\left(F_{3,69}=10.2, P<.001\right.$; Figure $3 \mathrm{~B})$. bKO mice traveled a longer path to the platform compared with the control 
groups $(P<.05)$. No differences were observed between control groups. There were no differences in swim speed during reversal. During the reversal probe trial, there was a main effect of gene $\left(F_{3,69}=4.3, P<.01 ;\right.$ Figure 3D). FLOX mice had shorter average distance to the target site compared with WT and bKO mice $(P<.05)$. No other differences were observed. Learning curves for WT vs bKO mice are shown in Figure 3F.

\subsection{Novel object recognition}

For time spent observing the novel object, there was a main effect of gene $\left(F_{3,56}=7.7, P<\right.$. 001; Figure 4). Post hoc tests showed that bKO mice spent less time with the novel object compared with control groups $(P<.05)$; the control groups did not differ from each other. No differences were observed in time spent with either object during the familiarization phase (percent time with familiar object that was replaced: control groups $=48.4 \% \pm 2.7 \%$; $\mathrm{bKO}=45.6 \pm 3.9, P<.6)$.

\subsection{Conditioned fear}

On day 1 , mice were conditioned to the tone-footshock pairing. On day 2 , there was a main effect of gene $\left(F_{3,60}=7.7, P<.01\right.$, Figure 4$)$ that was the result of bKO mice spending less time freezing than WT and FLOX mice in the training context (contextual fear). Nestin mice did not show a significant difference from other groups. On day 3, there was a main effect of gene $\left(F_{3,64}=10.3, P<.001\right.$, Figure 5$)$; bKO mice spent less time freezing to the tone (cued fear) than WT and FLOX mice.

\section{4 | DISCUSSION}

The study was conducted to determine if cognitive deficits observed in ubiquitous SIc6a ${ }^{-1 y}$ mice were influenced by deficits caused by the lack of peripheral $\mathrm{Cr}$. The results show that Nestin-cre::Slc6a $8^{\text {flox/y }}$ mice have robust learning and memory deficits, similar to Slc6a $8^{-/ y}$ mice but in the absence of body weight reductions or slow swimming. This would suggest that the effects seen in $S / c 6 a 8^{-/ y}$ mice are due to a lack of cerebral $\mathrm{Cr}$.

Similar to the ubiquitous $S l c 6 a 8^{-/ y}$ mice, bKO mice show learning and memory deficits in the MWM, NOR and conditioned fear, suggesting that these mice have wide-ranging cognitive deficits. This supports the hypothesis that these mice are a high-fidelity model since CTD patients appear to show a global cognitive delay. ${ }^{1}$ In contrast to $S / c 6 a 8^{-/ y}$ mice, the MWM deficits appeared without differences in swim speed. Interestingly, the bKO mice had deficits in the cued platform phase, which is a control procedure for swimming performance. However, given a lack of swim speed changes during hidden platform testing, it is unlikely that the cued effect is carrying over to the spatial learning phases of the test. It is also unlikely that the hyperactivity seen in the bKO mice played a role in MWM performance, as land-based hyperactivity does not often translate to increases in exploration in water-based tasks. ${ }^{16}$ In addition, female $S I c 6 a 8^{+/-}$mice were hyperactive and did not show deficits in NOR or conditioned fear. Further, the data from all models used to date have provided converging evidence of cognitive deficits in both the presence and absence of hyperactivity. Taken together, it is possible but unlikely that the hyperactivity plays a significant role in the cognitive deficits observed. 
Attention deficit/hyperactivity disorder has been reported in many CTD patients. ${ }^{22}$

Ubiquitous $S I c 6 a 8^{-/ y}$ mice showed initial hypoactivity followed by no difference in an openfield test compared with WT mice. In contrast, bKO mice were hyperactive. In these studies, a photobeam system was used to determine movement. It is possible that the smaller stature of the $S 1 c 6 a 8^{-/ y}$ mice lead to fewer beam interruptions but the exact cause is unknown. The presence of hyperactivity in these mice represent a new finding in our mice that is present in the CTD population, making the bKO mice a viable model for certain aspects of CTD.

Slc6a8 ${ }^{-/ y}$ mice are smaller than $S 1 c 6 a 8^{+/ y}$ mice which is similar to mice that are deficient in Cr synthesis. ${ }^{23,24}$ The reduction in size is in agreement with human data, as recent case reports show that hypotonia is a phenotype in many CTD patients, ${ }^{22}$ suggesting that the reduced size of the $S I c 6 a 8^{-/ y}$ mouse matches the effects found in many cases of CTD. Interestingly, Slc6a $8^{-/ y}$ mice have increased body fat percentages compared with $S l c 6 a 8^{+/ y}$ mice, ${ }^{25}$ which could suggest a loss of muscle mass in the mice. Both CNS and peripheral systems contribute to body mass. The finding of normal body mass in the bKO mice suggests that body fat changes are peripherally mediated and not due to a loss of hypothalamic $\mathrm{Cr}$. This is further supported by a recent study where adipose tissue-specific deletion of the Cr-synthesis precursor Arginine:glycine amidinotransferase (Agat or Gatm) increased body fat in mice. ${ }^{26}$

Brain $\mathrm{Cr}$ levels were reduced in the bKO mice while $\mathrm{Cr}$ levels in other tissues were spared. This suggests that there was no carry-over effect using the Nestin-cre in other tissues. There was a small decrease in brain $\mathrm{Cr}$ in the Nestin-cre mice. The reduction in brain $\mathrm{Cr}$ did not appear to influence the behavior of the animals. This is not surprising because female SIc6a $8^{+/}$mice only have mild cognitive impairments despite a 50\% reduction in brain $\mathrm{Cr}$ levels. ${ }^{14}$ Interestingly, there was an increase in the $\mathrm{Cr}$ synthesis precursor GAA in the brains of the bKO mice. This supports the hypothesis that the rodent brain can synthesize $\mathrm{Cr}$ and uses the Slc6a8 to shuttle $\mathrm{Cr}$ intermediates between cells. ${ }^{27}$ With a few exceptions, elevations in GAA levels are not observed in the urine and CSF of CTD patients, ${ }^{1,28,29}$ This does not exclude the possibility of increased GAA in the brain of CTD patients, but these findings do warrant further study into determine if and how the brain synthesizes $\mathrm{Cr}$ and what impact this has for CTD patients. CTD patients supplemented with Cr-synthesis precursors arginine and glycine did not show an increase in cerebral Cr levels. ${ }^{30,31}$ If this system can be better understood, it is possible that future treatment could involve enhancing this treatment protocol to somehow initiate endogenous $\mathrm{Cr}$ synthesis in the brain.

Choosing the proper model for understanding CTD is of utmost importance for understanding this disorder and developing treatments. The bKO mice used in this study represent the fifth genetic model of CTD examined. Three have come from the Slc6a $8^{\text {flox/y }}$ mice used in this study and 2 from the $S I c 6 a 8(5-7)^{\text {flox } / y}$ mice. In addition to the bKO mice from this study and the $S 1 c 6 a 8^{-/ y}$ mice from Skelton et al, ${ }^{5}$ Kurosawa et al ${ }^{8}$ generated Camk2a-cre::Slc6a8 ${ }^{\text {flox/y }}$ mice, creating a forebrain-specific Slc6a8 knockout. ${ }^{9}$ These mice showed a reduction in object recognition memory but modest deficits in the MWM that were only seen on when the last 3 days of testing were analyzed separately from the overall ANOVA. In contrast, the learning curves of the WT and bKO mice (Figure 3E) show that the deficits began on day 1 in the acquisition phase. This is similar to what is seen in the 
SIc6a $8^{-/ y}$ mice, suggesting that the bKO mice recapitulate the learning deficits seen in the ubiquitous Slc6a $8^{-/ y}$ mouse and in CTD. Along with the selective elimination of the Slc6a8 gene, the smaller spatial learning deficit seen in the Kurosawa et al's article may be due to the presence of some Cr during brain development in the Camk2a-cre::Slc6a $8^{\text {flox/y }}$ mice. Camk2a-cre expression is not observed until approximately postnatal day $3,{ }^{32,33}$ allowing for the presence of $\mathrm{Cr}$ during critical periods of brain development. Further, as the elimination of $\mathrm{Cr}$ is approximately $3 \%$ per day, ${ }^{34} \mathrm{Cr}$ could be present at high levels for several weeks even after Slc6a8 deletion in the Camk2a-cre::Slc6as ${ }^{\text {flox/y }}$ mice. The importance of $\mathrm{Cr}$ in brain development has been highlighted in a recent study showing that the loss of $\mathrm{Cr}$ kinase leads to aberrant neuronal development. ${ }^{35} \mathrm{In}$ addition, maternal $\mathrm{Cr}$ supplementation in rats enhanced hippocampal neuron development and improved long-term potentiation. ${ }^{36}$ Taken together, these data suggest that using Nestin-cre mice to generate brain-specific Slc6a8 disruption is more comparable to the ubiquitous $S / c 6 a 8^{-/ y}$ mice.

Baroncelli et al ${ }^{13}$ showed that a Nestin-cre-generated brain-specific knockout of exons 5 to 7 of the Slc6a8 gene resulted in NOR and spontaneous alternation deficits. Ubiquitous deletion of the same region results in MWM deficits, but only when the last 3 days of testing were examined separately. ${ }^{12}$ Interestingly, this deficit did not fully replicate in a subsequent study when similarly aged mice showed a deficit only on day 5 of testing. ${ }^{13}$ This would suggest that both our ubiquitous and our bKO mice have more severe spatial learning deficits than the ubiquitous 5 to 7 deletion. The brain-specific knockout of exons 5 to 7 mice were not evaluated in the MWM. The difference in spatial learning between the 2 Slc6a8 knockouts could also be explained by differences in the test apparatus or procedures; for example, platform to arena size ratio in these studies differ. We used a 144:1 tank-toplatform ratio for the acquisition phase, ${ }^{5,14}$ while the Baroncelli studies had a 93.4:1 tankto-platform ratio. Smaller search ratios simplify the task, ${ }^{16}$ perhaps making the lower ratio apparatus less sensitive. Rectifying these differences could provide additional information about this disorder by relating different mutation to known variants in human CTD. This could prove to be difficult as there is a great deal of heterogeneity in CTD-causing mutations. ${ }^{1}$

In conclusion, the results of this study show that the cognitive deficits in ubiquitous Slc $6 \mathrm{a}^{-/ \mathrm{y}}$ mice are attributable to changes in cognitive function and are not caused by being

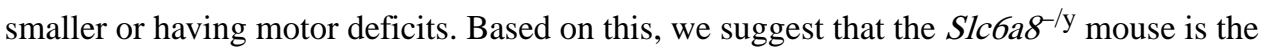
best model of human CTD. While smaller stature is not always observed in human CTD, all CTD patients have ubiquitous deletion of the gene. Brain-specific models are generated using neuronal precursors that likely allow for the expression of the Slc6a8 gene at the blood brain barrier (BBB). At the BBB, Slc6a8 is expressed in microcapillary endothelial cells and not on astrocytic feet that encompass the majority of the BBB. ${ }^{37}$ These cells derive from a mesodermal lineage and any neuronal model of Cre expression would not target them, allowing for Slc6a8 expression at the BBB. Taken together, the bKO data support that, regardless of the model used, ubiquitous Slc6a8 knockout mice are the preferred model of CTD; whereas the bKO models should be limited to studies to provide evidence that the ubiquitous model is not confounded. Therefore, the ubiquitous model should be utilized to develop potential therapeutics for this disorder. 


\section{ACKNOWLEDGMENTS}

The study was supported by NIH Grant HD080910. The authors thank Zuhair Abdulla, Keila Miles and Marla Perna for their helpful comments on the manuscript.

Funding information

Eunice Kennedy Shriver National Institute of Child Health and Human Development, Grant/ Award number: HD080910

\section{REFERENCES}

1. van de Kamp JM, Betsalel OT, Mercimek-Mahmutoglu S, et al. Phenotype and genotype in 101 males with X-linked creatine transporter deficiency. J Med Genet. 2013;50(7):463-472. [PubMed: 23644449]

2. Almeida LS, Rosenberg EH, Verhoeven NM, Jakobs C, Salomons GS. Are cerebral creatine deficiency syndromes on the radar screen? Future Neurol. 2006;1:637-649.

3. Clark AJ, Rosenberg EH, Almeida LS, et al. X-linked creatine transporter (SLC6A8) mutations in about 1\% of males with mental retardation of unknown etiology. Hum Genet. 2006;119:604-610. [PubMed: 16738945]

4. Rosenberg EH, Almeida LS, Kleefstra T, et al. High prevalence of SLC6A8 deficiency in X-linked mental retardation. Am J Hum Genet. 2004;75:97-105. [PubMed: 15154114]

5. Skelton MR, Schaefer TL, Graham DL, et al. Creatine transporter (CrT; Slc6a8) knockout mice as a model of human CrT deficiency. PLoS One. 2011;6:e16187. [PubMed: 21249153]

6. deGrauw TJ, Cecil KM, Byars AW, Salomons GS, Ball WS, Jakobs C. The clinical syndrome of creatine transporter deficiency. Mol Cell Biochem. 2003;244:45-48. [PubMed: 12701808]

7. Pyne-Geithman GJ, DeGrauw TJ, Cecil KM, et al. Presence of normal creatine in the muscle of a patient with a mutation in the creatine transporter: a case study. Mol Cell Biochem. 2004;262:3539. [PubMed: 15532707]

8. Kurosawa Y, Degrauw TJ, Lindquist DM, et al. Cyclocreatine treatment improves cognition in mice with creatine transporter deficiency. J Clin Invest. 2012;122(8):2837-2846. [PubMed: 22751104]

9. Tsien JZ, Chen DF, Gerber D, et al. Subregion- and cell type-restricted gene knockout in mouse brain. Cell. 1996;87:1317-1326. [PubMed: 8980237]

10. Tronche F, Kellendonk C, Kretz O, et al. Disruption of the glucocorticoid receptor gene in the nervous system results in reduced anxiety. Nat Genet. 1999;23:99-103. [PubMed: 10471508]

11. Oaks AW, Zamarbide M, Tambunan DE, et al. Cc2d1a loss of function disrupts functional and morphological development in forebrain neurons leading to cognitive and social deficits. Cereb Cortex. 2017;27: 1670-1685. [PubMed: 26826102]

12. Baroncelli L, Alessandri MG, Tola J, et al. A novel mouse model of creatine transporter deficiency. F1000Res. 2014;3:228. [PubMed: 25485098]

13. Baroncelli L, Molinaro A, Cacciante F, et al. A mouse model for creatine transporter deficiency reveals early onset cognitive impairment and neuropathology associated with brain aging. Hum Mol Genet. 2016;25(19):4186-4200. [PubMed: 27466184]

14. Hautman ER, Kokenge AN, Udobi KC, Williams MT, Vorhees CV, Skelton MR. Female mice heterozygous for creatine transporter deficiency show moderate cognitive deficits. J Inherit Metab Dis. 2014;37: 63-68. [PubMed: 23716276]

15. Brooks SP, Dunnett SB. Tests to assess motor phenotype in mice: a user's guide. Nat Rev Neurosci. 2009;10:519-529. [PubMed: 19513088]

16. Vorhees CV, Williams MT. Morris water maze: procedures for assessing spatial and related forms of learning and memory. Nat Protoc. 2006;1:848-858. [PubMed: 17406317]

17. Clark RE, Zola SM, Squire LR. Impaired recognition memory in rats after damage to the hippocampus. J Neurosci. 2000;20:8853-8860. [PubMed: 11102494] 
18. Podhorna J, Brown RE. Strain differences in activity and emotionality do not account for differences in learning and memory performance between C57BL/6 and DBA/2 mice. Genes Brain Behav. 2002;1: 96-110. [PubMed: 12884980]

19. Peters J, Dieppa-Perea LM, Melendez LM, Quirk GJ. Induction of fear extinction with hippocampal-infralimbic BDNF. Science. 2010;328: 1288-1290. [PubMed: 20522777]

20. Trotier-Faurion A, Dezard S, Taran F, Valayannopoulos V, de Lonlay P, Mabondzo A. Synthesis and biological evaluation of new creatine fatty esters revealed dodecyl creatine ester as a promising drug candidate for the treatment of the creatine transporter deficiency. J Med Chem. 2013;56:5173-5181. [PubMed: 23697594]

21. Benjamini Y, Krieger AM, Yekutieli D. Adaptive linear step-up procedures that control the false discovery rate. Biometrika. 2006;93: 491-507.

22. Dunbar M, Jaggumantri S, Sargent M, Stockler-Ipsiroglu S, van Karnebeek CD. Treatment of Xlinked creatine transporter (SLC6A8) deficiency: systematic review of the literature and three new cases. Mol Genet Metab. 2014;112:259-274. [PubMed: 24953403]

23. Choe CU, Nabuurs C, Stockebrand MC, et al. L-arginine:glycine amidinotransferase deficiency protects from metabolic syndrome. Hum Mol Genet. 2013;22:110-123. [PubMed: 23026748]

24. Schmidt A, Marescau B, Boehm EA, et al. Severely altered guanidino compound levels, disturbed body weight homeostasis and impaired fertility in a mouse model of guanidinoacetate $\mathrm{N}$ methyltransferase (GAMT) deficiency. Hum Mol Genet. 2004;13:905-921. [PubMed: 15028668]

25. Perna MK, Kokenge AN, Miles KN, et al. Creatine transporter deficiency leads to increased whole body and cellular metabolism. Amino Acids. 2016;48:2057-2065. [PubMed: 27401086]

26. Kazak L, Chouchani ET, Lu GZ, et al. Genetic depletion of adipocyte creatine metabolism inhibits diet-induced thermogenesis and drives obesity. Cell Metab. 2017;26(4):660-671.e3. [PubMed: 28844881]

27. Braissant O, Henry H, Beard E, Uldry J. Creatine deficiency syndromes and the importance of creatine synthesis in the brain. Amino Acids. 2011;40(5):1315-1324. [PubMed: 21390529]

28. van de Kamp JM, Jakobs C, Gibson KM, Salomons GS. New insights into creatine transporter deficiency: the importance of recycling creatine in the brain. J Inherit Metab Dis. 2012;36(1):155156. [PubMed: 22968583]

29. van de Kamp JM, Pouwels PJ, Aarsen FK, et al. Long-term follow-up and treatment in nine boys with X-linked creatine transporter defect. J Inherit Metab Dis. 2012;35:141-149. [PubMed: 21556832]

30. Jaggumantri S, Dunbar M, Edgar V, et al. Treatment of creatine transporter (SLC6A8) deficiency with oral s-adenosyl methionine as adjunct to L-arginine, glycine, and creatine supplements. Pediatr Neurol. 2015;53:360-363.e2. [PubMed: 26205312]

31. Valayannopoulos V, Boddaert N, Chabli A, et al. Treatment by oral creatine, L-arginine and Lglycine in six severely affected patients with creatine transporter defect. J Inherit Metab Dis. 2012;35: 151-157. [PubMed: 21660517]

32. Burgin KE, Waxham MN, Rickling S, Westgate SA, Mobley WC, Kelly PT. In situ hybridization histochemistry of $\mathrm{Ca} 2+/$ calmodulin-dependent protein kinase in developing rat brain. J Neurosci. 1990;10:1788-1798. [PubMed: 2162385]

33. Guo H, Mao C, Jin XL, et al. Cre-mediated cerebellum- and hippocampus-restricted gene mutation in mouse brain. Biochem Biophys Res Commun. 2000;269:149-154. [PubMed: 10694492]

34. Wyss M, Kaddurah-Daouk R. Creatine and creatinine metabolism. Physiol Rev. 2000;80:11071213. [PubMed: 10893433]

35. Fukumitsu K, Fujishima K, Yoshimura A, Wu YK, Heuser J, Kengaku M. Synergistic action of dendritic mitochondria and creatine kinase maintains ATP homeostasis and actin dynamics in growing neuronal dendrites. J Neurosci. 2015;35:5707-5723. [PubMed: 25855183]

36. Sartini S, Lattanzi D, Ambrogini P, et al. Maternal creatine supplementation affects the morphofunctional development of hippocampal neurons in rat offspring. Neuroscience. 2016;312:120129. [PubMed: 26592720]

37. Braissant O, Henry H. AGAT, GAMT and SLC6A8 distribution in the central nervous system, in relation to creatine deficiency syndromes: a review. J Inherit Metab Dis. 2008;31(2):230-239. [PubMed: 18392746] 
(A)

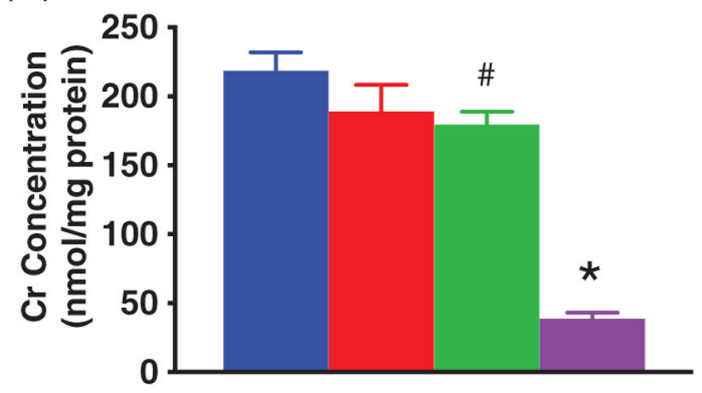

(C)

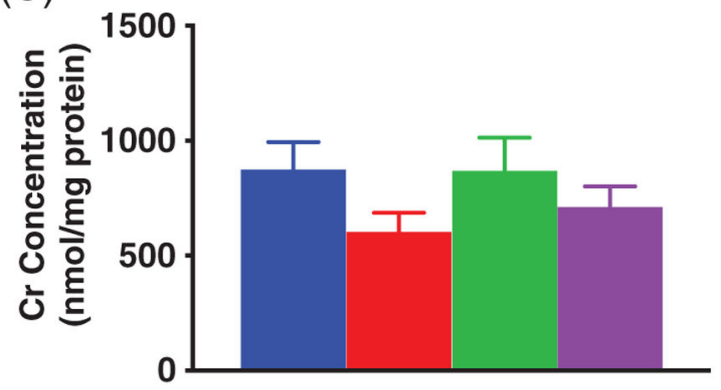

(E)

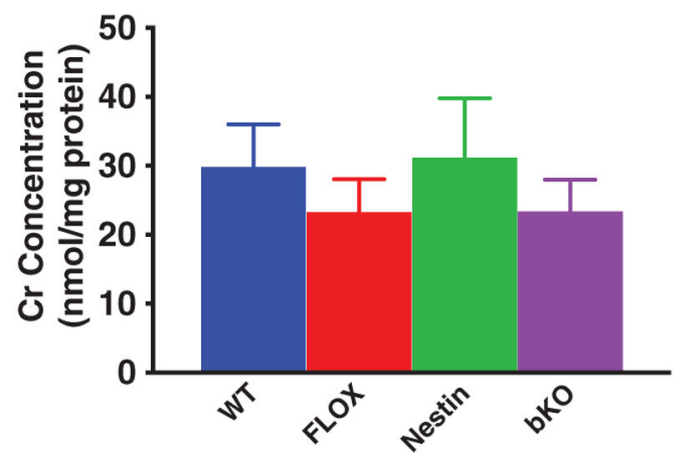

(B)

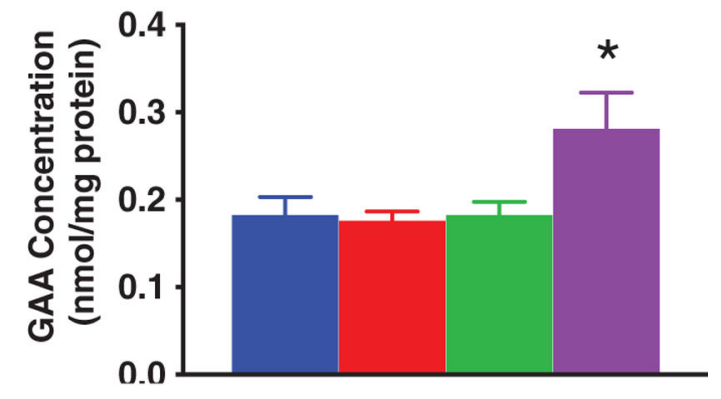

(D)

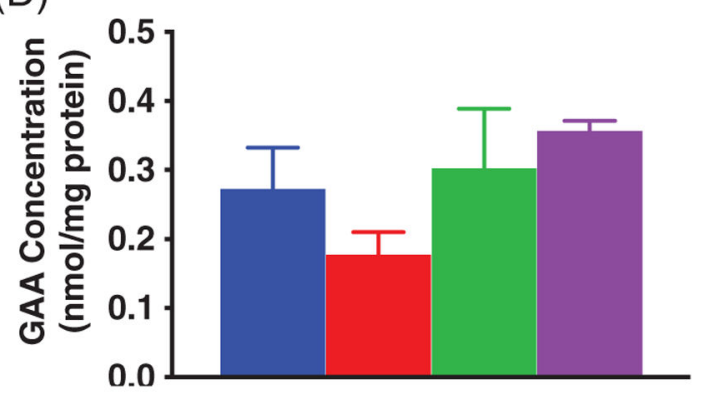

$(\mathrm{F})$

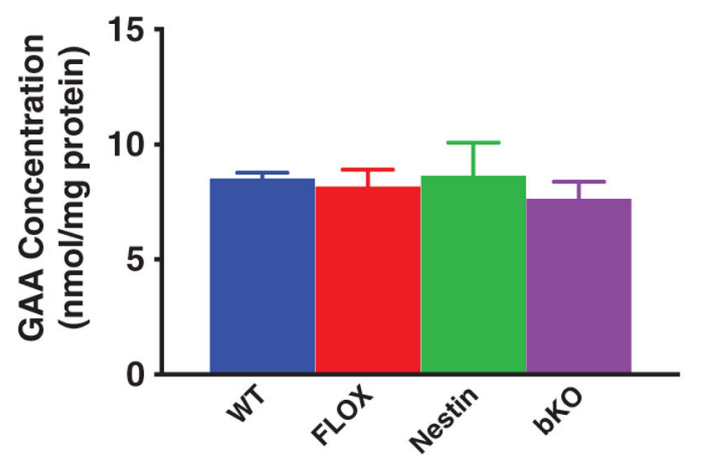

\section{FIGURE 1.}

Creatine and GAA levels in the brain, heart and kidney. A, BKO mice show reduced brain $\mathrm{Cr}$ levels compared with all control groups. Nestin mice had lower $\mathrm{Cr}$ levels than WT mice. $\mathrm{B}, \mathrm{GAA}$ levels are increased in the brain of bKO mice. In the heart and kidney, $\mathrm{Cr}(\mathrm{C}$ and $\mathrm{E}$, respectively) and GAA (D and F) levels are unchanged. $N=5$ /group. Mean \pm SEM. $* P<.05$ vs WT, FLOX and NESTIN, ${ }^{\#} P<.05$ vs WT 


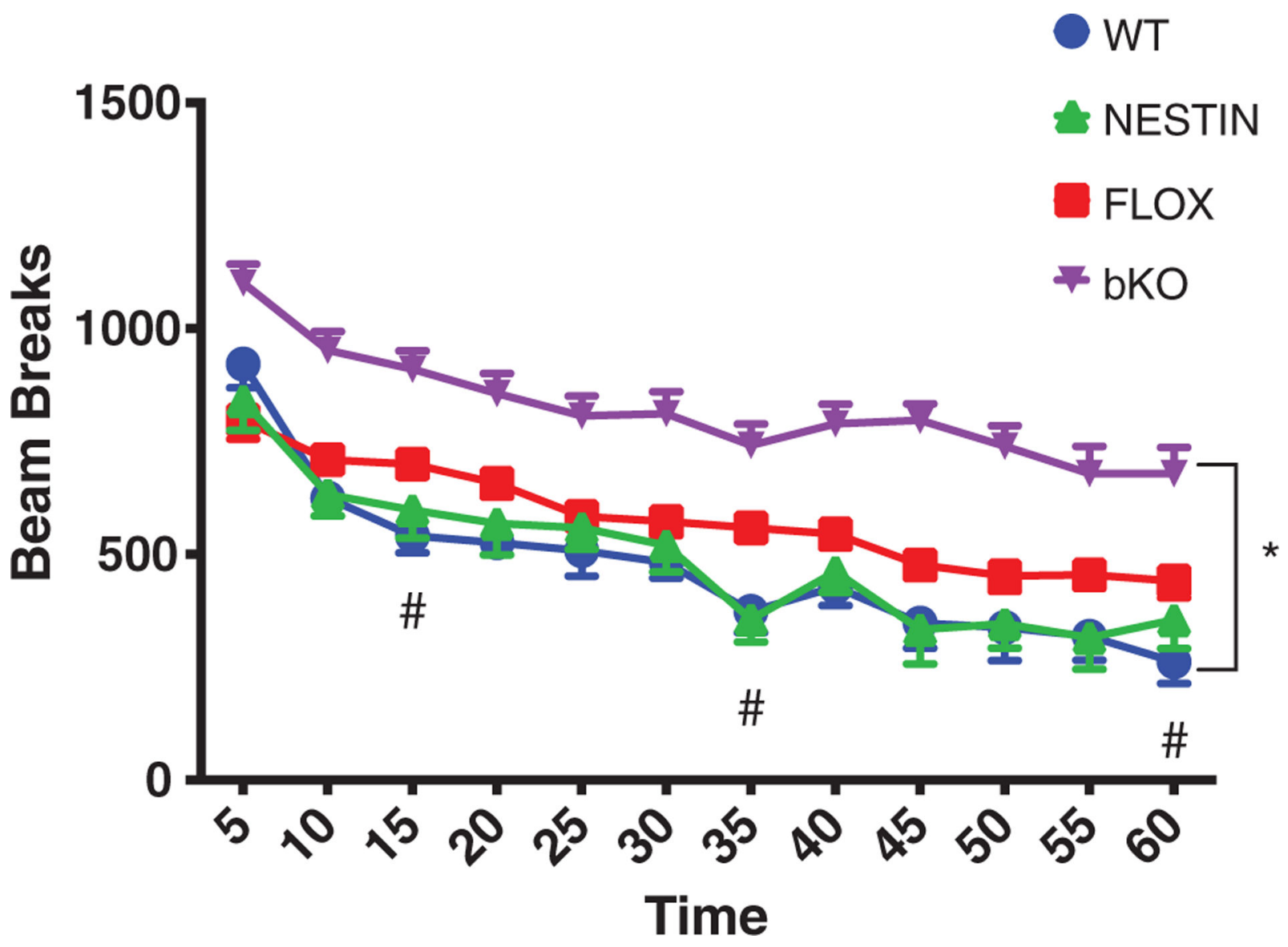

FIGURE 2.

Hyperactivity in Slc6a8bKO mice. bKO mice show increased activity compared with FLOX and WT mice. FLOX mice showed increased activity compared with WT mice at 15 and 35 minutes. Data are presented as mean \pm SEM. ${ }^{*} P<.05$ vs FLOX, Nestin and WT; ${ }^{\#} P<.05$ vs WT and Nestin 
(A)

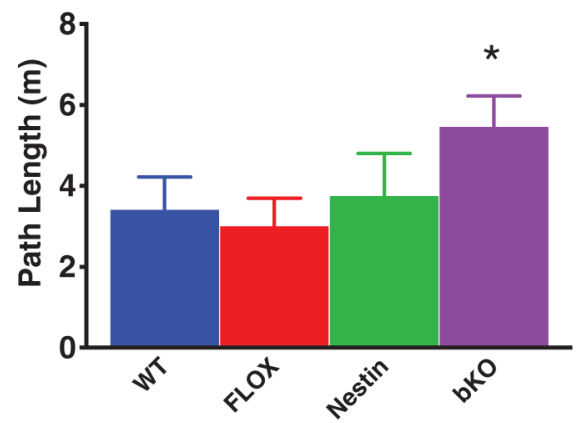

(C)

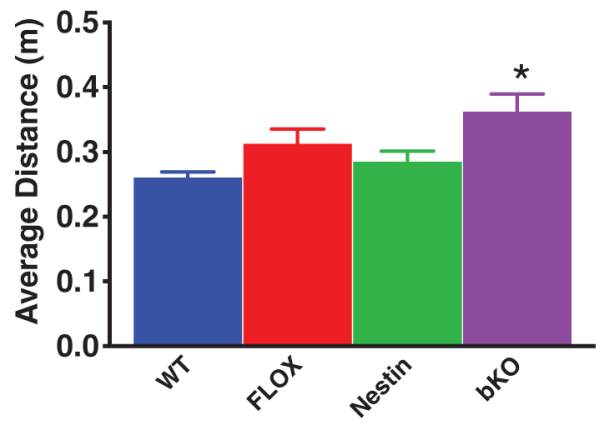

(E)

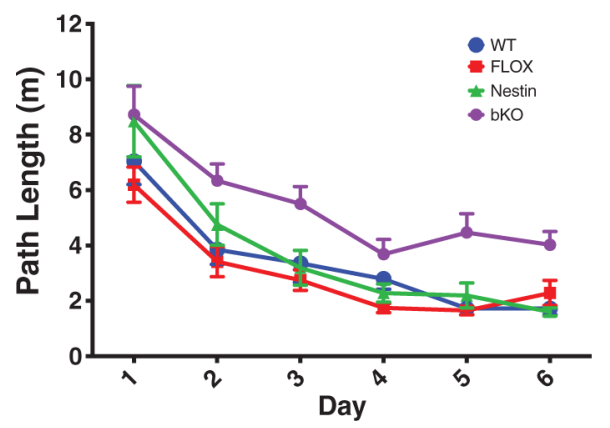

(B)

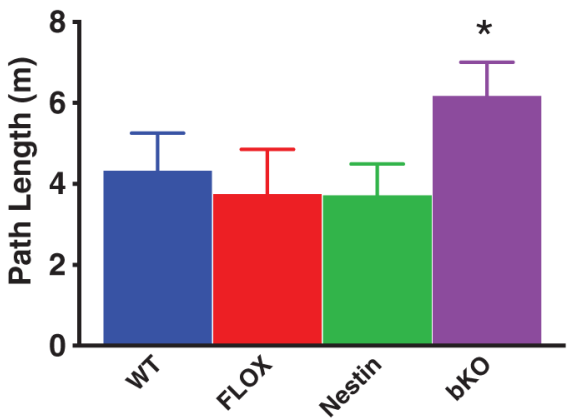

(D)

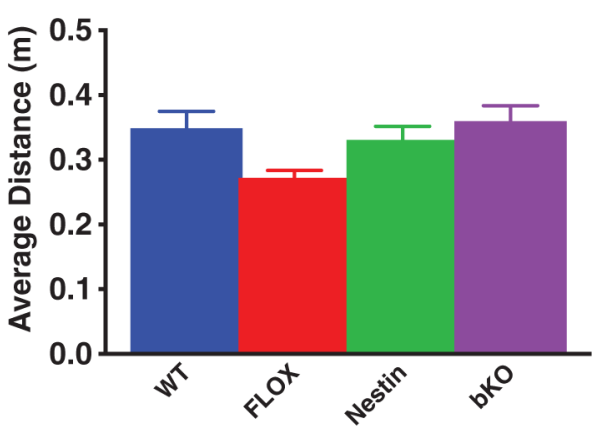

(F)

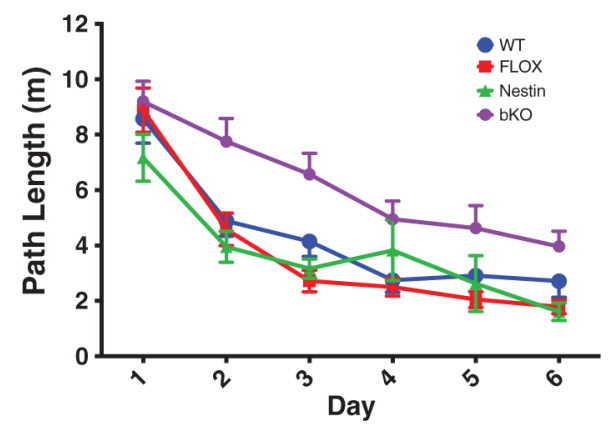

FIGURE 3.

Spatial learning deficits in the MWM. bKO mice have increased path length to the platform during the acquisition (A) and reversal (B) phases of the MWM compared with WT and FLOX mice. On probe trials, bKO mice showed a higher average distance from the platform compared with controls during the acquisition phase (C) but not during the reversal phase (D). Learning curves by day for the bKO and WT mice during the acquisition (E) and reversal $(F)$ hidden platform trials. Data are presented as mean \pm SEM. $* * P<.01$ vs FLOX and WT; $* P<.05$ vs FLOX and WT 


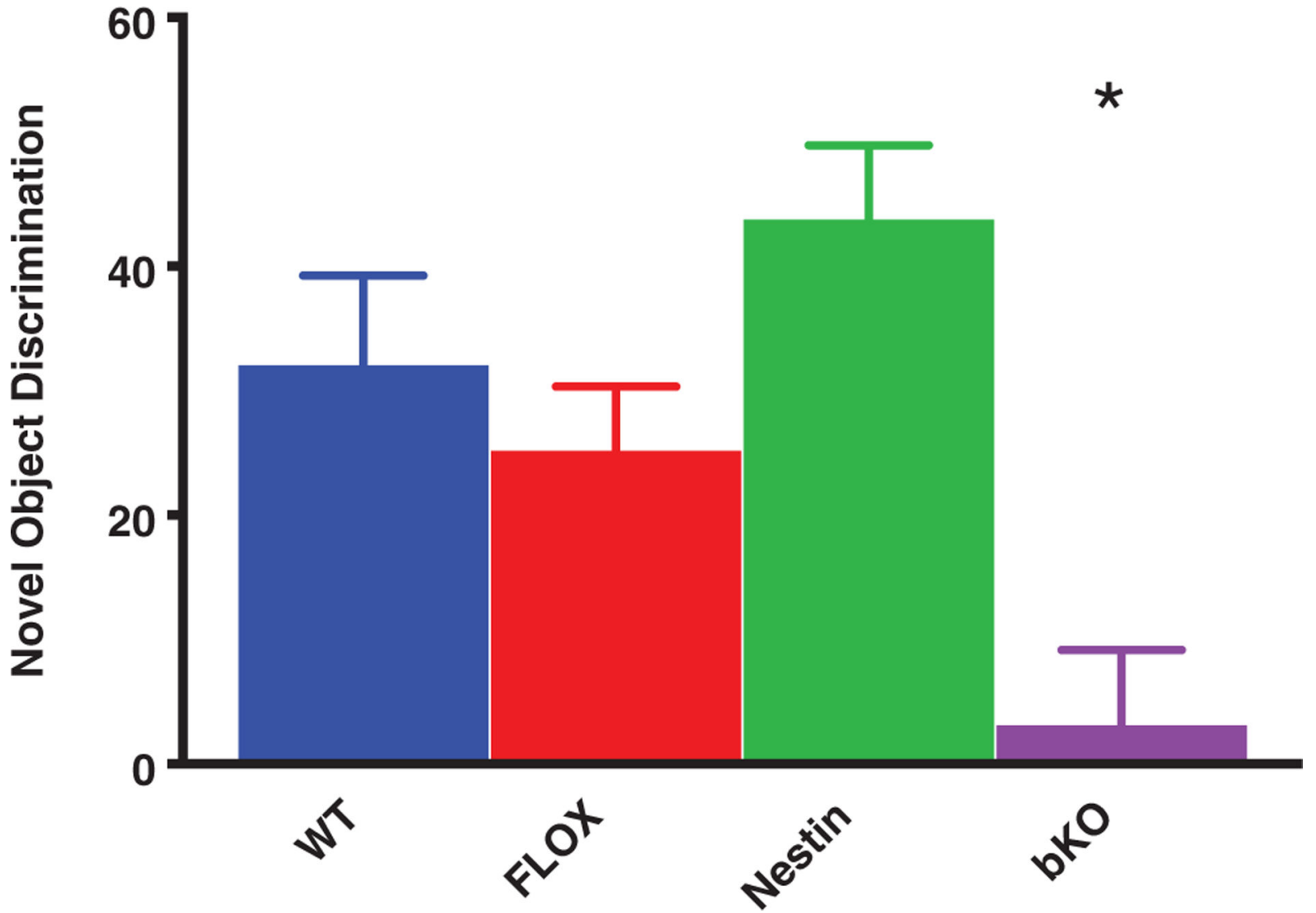

FIGURE 4.

Object recognition memory deficits. bKO mice had a reduced discrimination index for the novel object compared with the control groups. Data are presented as mean \pm SEM. $* P<.05$ vs WT, FLOX and Nestin 


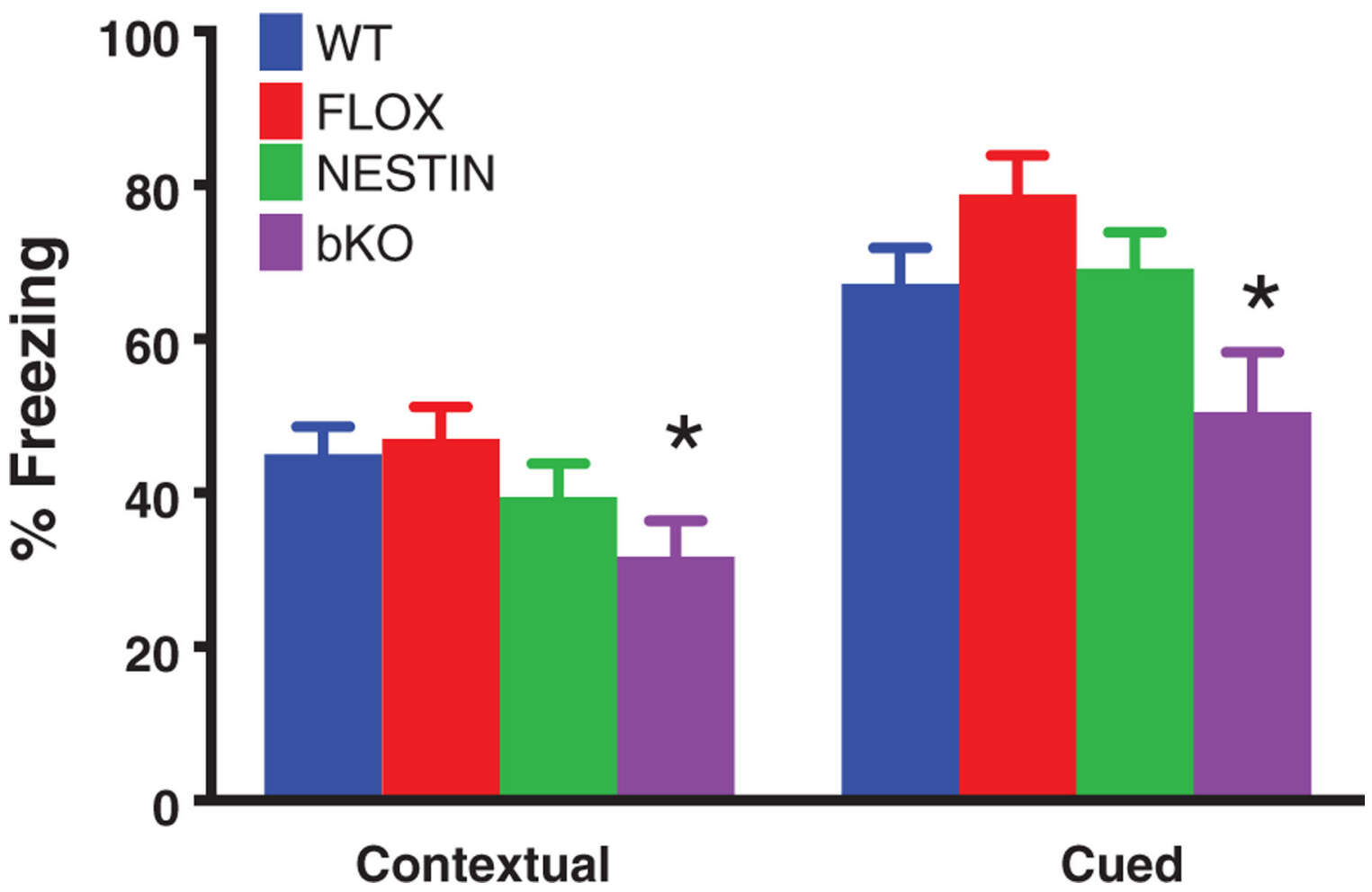

FIGURE 5.

Contextual and conditioned fear deficits in S/c6a8 bKO mice. bKO mice showed reduced freezing compared with control groups during both the contextual and cued phases of testing. Data are presented as mean \pm SEM. $* * P<.01$ vs FLOX and WT 